This item was submitted to Loughborough's Research Repository by the author.

Items in Figshare are protected by copyright, with all rights reserved, unless otherwise indicated.

\title{
Agents of the network society: spatial mobility patterns among managerial and professional workers
}

\section{PLEASE CITE THE PUBLISHED VERSION}

http://www.e-elgar.com/shop/eep/preview/book/isbn/9781783475582/

\section{PUBLISHER}

Edward Elgar Publishing @ Adrian Wilkinson, Donald Hislop and Christine Coupland

\section{VERSION}

SMUR (Submitted Manuscript Under Review)

\section{PUBLISHER STATEMENT}

This work is made available according to the conditions of the Creative Commons Attribution-NonCommercialNoDerivatives 4.0 International (CC BY-NC-ND 4.0) licence. Full details of this licence are available at: https://creativecommons.org/licenses/by-nc-nd/4.0/

\section{LICENCE}

CC BY-NC-ND 4.0

\section{REPOSITORY RECORD}

Hislop, Donald. 2019. "Agents of the Network Society: Spatial Mobility Patterns Among Managerial and Professional Workers". figshare. https://hdl.handle.net/2134/23559. 


\section{Agents of the Network Society: Spatial Mobility Patterns among Managerial and}

\section{Professional Workers}

Published as a chapter in: Wilkinson, Hislop, Coupland (2016) Perspectives on Contemporary Professional Work: Challenges and Experiences, Edward Elgar (ISBN: $9781783475575)$

Donald Hislop, School of Business and Economics, Loughborough University

\section{Introduction}

Spatial mobility has historically been an intrinsic element of a number of jobs, such as driving, or sales work. However, many contemporary writers argue that for a growing proportion of workers, the need to undertake work-related journeys between diverse locations is an increasingly important element of their work. For example, Faulconbridge et al (2009) argue that such mobility patterns help 'produce' global firms. Similarly, an intrinsic element of Castells' (1996) concept of the network society is that the 'flow' of workers (as well as objects, knowledge, information, culture) plays a key role in sustaining and reproducing contemporary business organizations. The focus here is narrowly on managerial and professional workers, who are argued to be a group of workers particularly affected by this trend towards increased levels of work-related spatial mobility. For example, lawyers and architects who work within global firms international business travel represents an intrinsic element of their work, and an activity they regularly undertake (Faulconbridge et al 2009). 
In examining work-related mobility an important distinction can be made between work-related travel and commuting, with commuting involving travel between a person's place of residence and their workplace, while work-related business travel involves travel between different locations that people are required to undertake in carrying out their work (Vartiainen et al 2007). The focus here is exclusively on workrelated business travel. In examining work-related mobility among managerial and professional workers it is more accurate to talk of mobilities, rather than mobility, as a heterogeneous range of different types and patterns of work-related travel are undertaken (Jones 2013). The fundamental aim of this chapter is to provide an overview of these patterns. While a number of typologies have been developed to distinguish between different types of work-related mobility (see for example Lilischkis 2003 and Wickham \& Vecchi 2010) it is argued here that a crucial, though neglected dimension of variation in work-related spatial mobility patterns is the spatial scale, or distances involved in work-related journeys. Fundamentally it is suggested that there is too narrow a focus on certain types of journey, specifically, long distance journeys involving plane-based travel which require people to stay away from home overnight. The chapter highlights how the spatial mobility of managerial and professional workers can involve undertaking quite different types of journeys on different spatial scales.

Thus, ultimately, in providing an overview of the work-related mobility patterns of managerial and professional workers it is argued that greater account needs to be taken of variations in spatial scale. The chapter begins in the following section examining the literature and statistics which are utilized to suggest that work-related mobility is an increasingly important feature of managerial and professional work. Following this, the chapter then explores the diversity in mobility patterns undertaken by managerial and 
professional workers. This is done firstly by presenting some statistics which highlights the varying extent to which particular types of managerial and professional workers undertake different types of work-related journeys. It is first suggested here that there is a particular, somewhat narrow focus on certain types of journey only. Secondly, a number of typologies are presented which have the aim of conceptualizing the diversity of work-related mobility patterns undertaken by managerial and professional workers. While these typologies highlight some important differences, they all neglect to adequately account for variations in spatial scale. This neglect is addressed in the third major section of the chapter which distinguishes between four spatial scales and type of work-related journey that are commonly undertaken by a range of managerial and professional workers. The chapter then closes with some general conclusions

The Contemporary Importance of Business-related Travel for Managerial and Professional Workers

Manuel Castells' (1996) concept of the network society represents one of the most influential ways to make sense of how society and the economy have been evolving over recent decades. This period has witnessed enormous developments in information and communication technologies (ICTs) that facilitate not only the sharing of vast quantities of information, but also rich forms of communication between geographically dispersed people. However, despite such developments, which arguably reduce the need for people to travel in order to collaborate with dispersed others, the same period has witnessed a significant increase in the mobility of money, goods, information, and 
people across the world. Castells uses the concept of 'flows' to encapsulate this, arguing that in modern society the flow of goods, people and information are expressions of the processes which dominate modern society (Knox et al 2008). In a similar vein, John Urry has outlined a similar vision utilising the concept of 'mobilities' (Urry 2000).

The focus here is on the spatial mobility of contemporary workers, with a specific and narrow focus on managerial and professional workers. In line with Castells' ideas about the importance of flows, many writers suggest that a need to travel regularly is an increasingly common requirement for many workers (Aguilera 2008, Bergström 2012, Jeong et al 2013, Vartianen et al 2007), with Hardill and Green arguing that, 'working life in most western economies is characterised by more and more movement' (2003, p. 212). In the introduction to their edited book on international business travel, Beaverstock et al make similar arguments, linking specifically to Castells, arguing that, 'in economic terms, business travel now appears to be the fundamental production process in constructing and reproducing the 'Network Society' and the global, knowledge-based economy that have come to be the hallmarks of contemporary capitalism', (2010, p. 2). Thus, as economic globalisation increases the level of international communication and collaboration between geographically dispersed people and organizations, the physical movement of people between locations represents a key mechanism sustaining and reproducing this activity.

However, despite the growing number of people making such claims a note of caution is necessary. Fundamentally, empirical data on both the number and proportion of contemporary workers who require to regularly travel for work, as well as how this has changed over time, is often limited and plagued by definitional challenges. For example, 
in attempting to estimate the number of mobile workers in the UK and Europe, Hislop \& Axtell (2007) compared data from two different European sources which produced significant different estimates based on different definitions. Thus one source suggested that in France and the Benelux countries there were over 850,000 mobile workers in 2002 , while another source gave an estimate of just over 500,000 for the same region in the same time period. Further, few sources present longitudinal data that provides empirical support for claims that levels of work-related mobility have increased over time. One of the few sources of such data is Felstead et al (2005), who analyze data from the UK government's national Labour Force Survey to show that in the UK, between 1981 and 2002, there was a more than $200 \%$ increase in the number of mobile workers. Beaverstock \& Faulconbridge (2010) provide another source of longitudinal data which supports claims regarding increasing levels of business travel, but again, utilize UK specific data. Their analysis of the UK Travel Trends survey showed that in the 10 years between 1997 and 2006 there had been a trebling in both the number of foreign travellers coming to the UK on business and the number of UK travellers going overseas for business purposes. Despite there being a small decline in both types of traveller between 2006 and 2013 (Travel Trends 2014), the number of business travellers coming to and leaving the UK for business purposes in 2013 was still significantly greater than in 1997.

In discussing contemporary patterns of work-related mobility a number of writers suggest managers and professionals have been particularly affected by the increasing need for work-related mobility (Aguilera 2008, Gustafson 2006, Hardill \& Green 2003, Jones 2010). The reasons why this is the case are examined immediately below. However, as with statistics on the level of work-related mobility among the general 
working population, detailed statistics on the work-related mobility patterns of managers and professionals are somewhat limited. Further, Aguilera (2008) estimates that even now only a significant minority of managers and professionals regularly require to travel for work. This is reinforced by the results of a number of surveys, with for example Gustafson (2006) finding that in a survey of Swedish workers from the late 1990s that just over $10 \%$ had to recently undertaken a work trip which involved at least one overnight stay. Similarly, Jeong et al (2013) in their survey of business travel in the USA from the early 2000 s found that $84 \%$ of women and $72 \%$ of men were classified as non-travellers, not having made any recent work-related trips involving an overnight stay. However, it needs to be acknowledged that these surveys don't take account of workers who travel for work, but do NOT require to stay away overnight in doing so. Thus arguably, these surveys underestimate the extent to which managers and professionals are mobile for work, by presenting data on one type of journey only. Finally, Cohen (2010) analyses data from the UK Labour Force Survey in 2006, which identified mobile workers as those who responded to questions on the location of work with the response, 'different places with the home as a base'. This found that among the three relevant occupational groups (managers, professionals and associate professionals) the proportion which were mobile was between 8-9\%. However, it should be noted that the definition of mobility used in this studies is somewhat narrow, as it excludes workers who are mobile but do not use their home as a base (which may include workers who use their office as a base, or who have no fixed base to work from). Thus a key limitation of all the surveys referred to above, when trying to calculate the overall proportion of managers and professionals who require to be mobile for work, is that they provide underestimates by utilizing somewhat narrow definitions which focus only on specific types of worker or journey. 
Overall therefore, while in recent years there has been an increase in the proportion of managerial and professional staff that require to travel for work, the vast majority of managers and professionals still do not require to travel for work. However, due to various definitional issues, arguably, all relevant survey data on this topic to some extent underestimate the proportion of managers and professionals who do regularly travel for work.

This section concludes by briefly examining some of the key reasons why a growing proportion of managers and professionals require to travel for work. Fundamentally, due to various inter-connected globalising and internationalising trajectories there is an increased need for geographically dispersed people and organizations to communicate and collaborate. Firstly, there has been a growth in the number, size and scale of international, multinational and global organizations which have offices and sites spread across diverse locations. While the different sites and business units within such organizations may have some, if not significant levels of autonomy, there is still a need for communication and collaboration between sites. For example, within such organizations there is a managerial need to travel to develop cross-site collaboration, create and develop corporate cultures, and impose some level of corporate control (Jones 2010). For service-based organizations, such internationalizing trajectories are partly driven by the internationalizing activities of their clients, which increasingly require/demand international levels of service and support. A good example of organizations affected by, and reinforcing these internationalizing trends are professional service firms like lawyers, accountants and management consultants, many 
of which have grown to operate on an international scale (see for example Faulconbridge \& Muzio 2008, 2012).

While, as outlined earlier, developments in ICTs have underpinned and facilitated communication between the people involved international collaborative activity, there is still a significant need for some level of face-to-face interaction between people, which is why levels of business travel among managers and professionals have increased. This is due to the benefits face-to-face interaction have over ICT-based communication and collaboration for both the development of trust, and secondly the sharing of highly tacit knowledge which is impossible to codify (Aguilera 2008, Salt 2009). Further, travel, and face-to-face communication is not only important for sustaining existing business relations, it is also useful, and arguably necessary for the development of new ones. For example, in some contexts being prepared to travel to the site of a potential client or collaborate for a face-to-face meeting can be interpreted as a sign of commitment which may help win business, or cement a developing collaboration (Gustafson 2012, Wickham \& Vecchi 2010).

Thus far, business travel has been discussed in general terms. However, a detailed examination of the topic reveals much diversity in factors such as the type of workers who typically require to be mobile, the extent to which people require to be mobile for work, and finally, the type and scale of the journeys that people undertake. The purpose of the following section is to provide insights into these diverse work-related mobility patterns. 
The Work-related Mobility Patterns of Managerial and Professional Workers

While acknowledging that levels of work-related mobility have increased in recent years, such general statements don't provide insights into the diversity in the type of mobility people undertake, the frequency with which they do it, and the type of worker engaging in this activity. In examining the heterogeneous types of work-related mobility engaged in by contemporary managerial and professional workers, this section is structured into two parts. Firstly it examines a range of statistical evidence on how mobility patterns vary for different types of worker, and secondly it examines a number of typologies which have been developed to conceptualize these patterns.

Statistics on Mobility Patterns among Managerial and Professional Workers

A first observation to make when looking at mobility patterns among managerial and professional workers, is to highlight the gendered nature of business travel. Fundamentally, a finding from virtually all surveys of business travel show that men are significantly more likely to travel for work than women (Aguilera 2008, Gustafson 2006, Jeong et al 2013). There are various explanations for this, including that men are more likely to be in the type of roles requiring business travel, and that women's greater level of domestic and childcare responsibilities inhibit their ability to travel for work.

For managerial and professional staff, a couple of surveys provide some useful insights into differences in mobility patterns. However, both the surveys reported below refer 
only to business travel involving at least one overnight stay. Gustafson (2006) presents the analysis of a large, nationally representative survey of travel patterns among Swedish workers from the late 1990s. Gustafson analysed differences in travel patterns by various factors including gender, age, family situation and education. Of most interest here are differences in mobility pattern by income level (See Table 1). Gustafson divided the survey cohort into three income groups (low, medium and high). If it is assumed that to some extent that income level is linked to hierarchical position, differences in mobility by income group provide some insights into how work-related travel is related to hierarchical position.

\section{Insert Table 1 about here}

The Pattern in Gustafson's data is clear, the higher a person's income (and the more senior their position), the more likely they are to travel for work. Thus while only $3 \%$ of low income workers travelled for work, $8 \%$ of medium income workers did and fully $25 \%$ of high income workers did. Jeong et al (2013) report the results of a similar survey of work-related travel involving an overnight stay among workers from the USA, and found remarkably similar findings, with those in executive roles most likely to travel for work, those in blue collar roles least likely to travel for work, with professional workers in the middle. Aguilera (2008) also suggests that the amount of work-related long distance travel undertaken is linked to levels of seniority.

However, in stark contrast to the above findings Cohen's (2010) analysis of the UK Labour Force Survey discussed above presents a different pattern. While, as outlined above, the proportion of managerial and professional occupations that is regularly 
mobile for work was, on average 8\%, for the 'skilled trades' occupational category the proportion of workers that is regularly mobile for work was $26 \%$. The 'skilled trades' category was broad and diverse including beauticians, taxi drivers, plumbers, window cleaners, gardeners and actors. However, in broad terms both occupational groups could be classified as representing skilled blue-collar work. Thus, Cohen's analysis suggests the opposite trend to Jeong et al (2013) and Gustafson (2006), with workrelated mobility being more likely among blue collar, than professional workers.

The explanation for this difference lies in the quite different types of mobility that are being considered. Gustafson (2006) and Jeong et al (2013) both focus narrowly on work-related travel involving at least one overnight stay. Arguably, if a journey requires an overnight stay it is likely not to be a localised journey and is more likely to be long distance, and potentially overseas journey. In contrast, the survey Cohen analysed did not specify the type of journey undertaken, simply asking people if they, 'worked in different places with the home as a base'. Such a definition of work-related mobility therefore includes a potentially wide-range of journey types, from short localised journeys, to international travel. Based on the type of jobs that are included in the skilled trades category (i.e. gardeners, plumbers, beauticians), the types of work-related mobility undertaken is likely to be of relatively short, localised journeys occurring within a small geographic area.

Overall therefore, while skilled trades people may be more likely than managers and professionals to engage in work-related travel, this is typically on a localised geographical scale. Further, international, long distance work-related mobility is more likely to be undertaken by managerial and professional staff, and the more senior the 
role, the more likely it is that they will need to travel internationally for work. This comparison highlights the importance of accounting for spatial scale in understanding differences in work-related mobility patterns, which is an issue returned to later in the chapter.

Conceptualizing Work-Related Mobility Patterns

The focus of this section now shifts to examine a number of typologies which have been developed to make sense of the diversity in work-related mobility patterns that exist. Three separate typologies are outlined, after which the section concludes by making a general critique of a common limitation shared by all three.

The first typology developed by Lilischkis (2003) differentiates between five distinctive types of mobility, which are labelled in terms of the type of workers who undertake them. Firstly, they refer to 'on-site movers', which refers to workers who require to regularly be mobile within the confines of a particular location or site. This can be labelled a very micro level of mobility with journeys between locations almost exclusively being taken on foot. In relation to managerial and professional workers, an example would be a doctor who physically moves around within a hospital, for example to visit patients in different wards or attend meetings in different locations. There are a potentially significant number of managers and professionals who undertake this type of mobility, and due to the size of some sites, the amount of travel involved may not be insignificant. However, this form of mobility in not particularly novel and is not a distinctive feature of contemporary globalized capitalism, and is this of limited 
relevance here. The second type of mobility type referred to by Lilischkis are 'carriers', who are workers responsible for the transportation of people or goods such as train drivers, couriers etc. Such workers are equivalent to the category of mobile workers Cohen (2006) referred to as involving, 'mobility as work'. However, as such workers are typically not categorized as managerial and professional, they are also of limited relevance here.

Lilischkis (2003) outlined three other types of work-related mobility that are relevant to managerial and professional workers, given the somewhat visual and creative labels of 'yoyos', 'pendulums' and 'nomads', with these three mobility patterns being differentiated by the extent to which they involve a static base. Firstly, 'yoyos' are workers who regularly require to travel to different locations for their work, but who have a fixed, static base such as a personal office that they always return to, which is their primary work location. In contrast, 'pendulums' are people who have to regularly travel for work, but who have two separate static locations that they can work from, such as their home plus a corporate office. Finally, 'nomads', as the label implies, are workers who regularly travel for work, but who have no static based from which they are based, continually working from different locations.

However, limitations of this typology are that it doesn't effectively take account of travel frequency, or the spatial scale of journeys that are undertaken. Thus, there is scope for significant variation within each of the three mobility types developed. For example yoyo's might vary significantly both in terms of the distances travelled and the frequency with which journeys need to be made and may include someone who only 
occasionally needs to make relatively short journeys, to someone who much more regularly needs to undertake long distance, international journeys.

The second typology considered here has some overlaps with, and may have been inspired by the typology of Lilischkis. It was developed by Wickham \& Vecchi (2010) based on their study of the mobility patterns of workers involved in the Dublin software industry. They refer to three types of mobility pattern based on two dimensions, the number of places that someone regularly has to visit, and the number of new/novel places that someone regularly has to visit. The first mobility patterns they label as 'commuter', which is where someone is low on both dimensions, only visiting one or two locations regularly, and rarely having to even visit other, new locations. For those working in the Dublin software industry, one of the main 'commuter' locations people travelled to regularly was the UK, with some people making weekly trips to the same one or two UK locations, for example to visit particular clients. The second mobility patterns they identify is labelled 'explorers' and involves someone slightly higher on both dimensions than a 'commuter'. Thus 'explorers' are people who both visit a number of different sites regularly, and also have to regularly visit new locations that they are unfamiliar with. People with this type of mobility pattern often had sales responsibilities, and would regularly have to visit new locations to visit prospective clients with the aim of winning a new contract. What is common to workers undertaking both these types of mobility pattern is that despite the regularly need to travel, they have a single static base from which they are located and to which they always return. 
The third and final mobility pattern in Wickham \& Vecchi's (2010) typology, which overlaps with Lilishkis' typology, is 'nomads'. This mobility pattern is somewhat different from the first two mobility patterns in their typology in that the people engaged in this type of mobility travel so much that they do not have a single identifiable location from which they are based. In Wickham \& Vecchi's (2010) typology nomads are people high on both scales, who regularly visit a large number of familiar sites, and simultaneously travel to a large number of new and new and unfamiliar locations. Wickham \& Vecchi suggest that the proportion of workers undertaking this type of mobility is relatively limited, and may be confined to very senior executive and business owners, who, due to their corporate level strategic role, regularly visit large numbers of existing clients, and also visit a large number of new locations, in order to try and help win work from prospective new clients. The main limitation of this typology is the neglect of the spatial dimension of people's mobility patterns. For example, there will be significant differences in the work and travel patterns of between Dublin-based workers who only have to travel to the UK, compared to those who may have to regularly travel to Southern Europe, and at a more extreme level, who regularly require to undertake inter-continental travel to visit locations in the USA or Asia.

A third typology worth mentioning briefly was developed to characterize the diverse 'portfolios of mobility' that workers within global multinationals undertake (Millar \& Salt 2008). The main variable differentiating between the types of mobility in this typology is time, more specifically, the length of time people spend away from their home. Thus Millar \& Salt differentiate between permanent overseas appointments, traditional longterm expatriate assignments (typically lasting about three years), short term assignments of 3-12 months, extended business travel involving trips lasting 
approximately 30-90 days, and traditional business travel, where a business trip may only involve staying away from home for a few days. Finally, they also refer to 'virtual mobility', which is where a worker, rather than physically travelling between locations, uses ICTs to travel 'virtually', through electronic communication and information sharing. This type of mobility links back to Castell's arguments regarding how the flow of information and knowledge represents a crucial aspect of contemporary economic activity.

All of the typologies thus far examined are successful in highlighting the heterogeneous character of the spatial mobility patterns engaged in by managerial and professional workers, and outline some key dimensions by which they vary, such as the range of locations visited, or the amount of time people spend away from home. However, they all inadequately take account of variability in the types of journey undertaken, and the diversity that exists in the distances travelled. As was outlined earlier, when comparing Cohen (2010) and Gustafson's (2006) data on travel frequency among managerial and professional staff, the type of journey undertaken and the distances travelled represented a crucial explanatory variable. The following section of the paper remedies this neglect through examining the variability in the type of journeys undertaken and distances travelled by managerial and professional workers.

Diverse Journey Types and Spatial Scales in the Work-related Mobility of Managerial and Professional Workers 
Even with a relatively narrow focus on managerial and professional staff, there is a wide diversity of work-related mobility patterns involving different spatial scales. Thus, not all work-related travel undertaken by such workers involves international mobility undertaken by plane and may involve more 'mundane' and localized car-based journeys between locations within a circumscribed geographic area. Taking adequate account of this diversity is important as journeys of different types and over different distances have different functions, characteristics and purposes and focussing purely on journeys of one type, such as long-distance journeys involving an overnight stay, means only a partial view of the work-related mobility of managerial and professional workers is revealed.

In distinguishing between journey types it is too simplistic to focus purely on the physical distance being travelled, although this is an important factor which influences journey time and a journey's characteristics. Other factors which also influence either the distance travelled or the character of the journey include the mode of transport being used, the day and time a journey is undertaken, how many (if any) time zones are crossed, whether direct travel is possible between the starting location and the final destination, the number of different journey stages involved, whether international borders are crossed and the visa-related implications of this, to name but a few. However, developing a typology of journey types that takes full account of all such variables is arguably too complex, thus some level of simplification is required. This is done here by combining the broad distances travelled on a journey and the primary mode of transport used, which results in a typology which distinguishes between four broad, overlapping journey types (see Figure 1). However, it requires to be 
acknowledged that within each broad journey type it is possible to differentiate between a variety of journey types.

It is useful to start by acknowledging that the type of journeys undertaken by managers and professionals are not all international trips, where large distances are travelled, involve plane-based travel or require an overnight stay. For example, journeys may not be long, may be undertaken by car or train, and may allow workers to return home at the end of the working day. In understanding such journeys a distinction is made between two journey types, localized land-based travel, and long distance land-based travel. Using the term land-based travel deliberately combines travel by car, train, ferry etc, each of which journey types have their own characteristics, and which produce a different travel experience. However, it is argued that in terms of journey type and their spatial scale, there is a broad similarity which distinguishes them from plane-based journeys. Further, in considering plane-based journeys which involve travelling on a greater spatial scale, over longer distances, a distinction is made between two types of journey: short-haul plane-based travel and long-haul plane-based travel. In the remainder of this section, each journey type is examined in more detail and an illustrative example of the mobility undertaken by managerial and professional staff of each journey type is presented.

\section{Localized Land-based Travel}

Firstly is localized travel, which is the most geographically constrained scale, occurring within a relatively small geographic area such as a particular town or suburb of a city. At this scale journeys are most likely to be undertaken by car and may involve professional 
workers visiting local customers or clients. This type of travel is very different in character from the international travel involving an overnight stay that is typically the focus of interest among academic studies of work-related mobility. At this spatial scale travel is over relatively short distances, journeys may not necessarily take a long time, and undertaking such journeys will in most cases not involve an overnight stay away from home. Often, workers undertaking such journeys may complete a number of separate, short journeys to different locations within a single day. Due to these characteristics therefore, the work-life balance implications of this form of travel are quite different and much less significant than international travel. However, due to factors such as traffic congestion, parking restrictions, travelling on over-crowded trains/busses or requirements to undertake a certain number of journeys in a particular day means that undertaking such journeys are not necessarily simple or stress free.

Two illustrate examples of professional workers involved in this form of mobility both relate to health and social care professionals (Ferguson 2009, Wibberley 2013). For example, Ferguson (2009) examines the case of social workers, many of whom make extensive use of cars in carrying out their work. The journeys undertaken are typically local, as within the UK social workers are employed by local government organizations which have responsibility over relatively small and specific geographic areas. Ferguson highlights how car-based mobility is necessary with this occupation as social workers require to travel from their offices to a range of different sites in order to meet and liaise with other health and social care workers as well as their clients. 
With long-distance land-based travel, work-related journeys while being undertaken by car, train etc, involve travelling significantly greater distances than with localized journeys. Thus, this type of journey can involve people undertaking quite long and timeconsuming journeys. For managerial and professional staff who regularly require to engage in this type of travel, the process of travel itself can start to involve significant amounts of time, may involve the same stresses as localized travel (congested road, over-crowded trains etc), but due to the amount of travel time involved, these journeys may also be a source of fatigue. In relation to managerial and professional workers, the type of people who engage in this type of travel are both professionals with a geographically dispersed client-base and responsibilities, or managers who have responsibilities for business within a number of locations (such as within a particular region, state or country). For such managers work-related travel may involve not only within company visits to different corporate sites, but also extra-company visits to clients, suppliers or strategic partners. The type of managers and professionals who regularly undertake this type of travel are likely to be at mid-to-senior level, being people with a reasonable amount of responsibility.

An example of this type of travel is provided by Hislop \& Axtell (2009), who analyse the work-related mobility of some management consultants. The paper examined consultants working for two separate organizations based in the North West of England, both of whom had clients dispersed widely within the UK. Thus, in order to travel to and work at client sites, consultants in these companies had to regularly undertake long and time consuming journeys and spent significant amounts of time in their cars. Thus, one consultant commented on this saying, 'you almost have a strange relationship with your 
car ... you spend hours and hours in it ... you sometimes get to the point where you know your car better than your wife or friends' (p. 68).

Ultimately, managers and professionals who regularly require to undertaken such journeys can experience work-life balance problems. This is due to a combination of the time involved in travelling, the necessity to often incorporate overnight stays within such trips, and the fact in order to fit the needs of clients that such journeys are often undertaken during traditional non-work time such as evenings or weekends, to make people available to work during conventional office hours. All these factors combined can thus result in workers spending significant amounts of time at evenings and weekends away from home, which may negatively impact on their non-work lives.

\section{Short-Haul plane-based Travel}

The third spatial scale that managers and professionals commonly travel over is shorthaul plane-based travel, where the predominant mode of transport on journeys is a plane, and undertaking journeys of a few hours in length. Such journeys are typically intra-continental (such as flying between countries within Europe), but in large nation states such as the USA or Australia, such journeys may occur within national borders. While flight times on such journeys may be relatively short, the process of navigating airport bureaucracies, combined with any travel required to get to or from the airport can mean such journeys may often be quite time consuming. Further, the practicalities of undertaking such journeys means that they require people to stay away from home for at least one night. Arguably, this is the type of journey that has been the 
predominant focus of academic attention (Beaverstock et al 2010, Faulconbridge et al 2009, Gustafson 2006, Jeong et al 2013). Finally, the non-work implications of requiring to regularly engage in this form of work-related mobility are both positive and negative. While on the negative side such journeys can be tiring and time consuming to undertake, and the need to be away from home regularly may impact negatively on people's non-work lives, such journeys also provide opportunities to combine workrelated travel with tourism.

Lassen's (2006) analysis of the work-related travel patterns of staff in two Danish knowledge organizations provides a useful illustration of this form of work-related travel. The two organizations examined are the Danish division of Hewlett-Packard and Aalborg University. In both organizations the focus was on managerial and professional workers, with for example the focus in Aalborg being on academic staff. Various difference in the travel patterns of staff from these organizations are revealed and analysed (such as the number of trips undertaken, and the extent to which people travel on their own or with family and/or colleagues). However, for the purposes of the analysis developed here, the type of journey undertaken by staff in both organizations are similar in spatial scale, being predominantly plane-based, where journeys were most typically made either within Scandinavia, or Europe. Thus for example, within Hewlett-Packard, only $7 \%$ of trips were outside of Europe, while only $22 \%$ of the trips undertaken by academics from Aalborg were outside of Europe.

The primary purpose of these journeys was to facilitate face-to-face interactions, whether this was with colleagues based in different locations, existing clients, or prospective clients. Undertaking such journeys involved experiencing, 'a life in 
corridors' (p.306), and the frequency with which people undertook such journeys typically meant they were experienced as routine and mundane rather than exciting. However, Lassen also identified some positive features business travellers derived from undertaking this form of work-related travel. Firstly, it allowed people to develop a 'cosmopolitan' identity as someone familiar with diverse cultures and practices.

Secondly, such journeys also provided various opportunities to combine work with nonwork and engage in tourist activities of diverse kinds, such as extending a trip by a few days to do sightseeing or to visit family and/or friends.

Long-Haul Plane-based Travel

Fourthly and finally, is long-haul, plane-based travel, which includes journeys on the largest spatial scale. At this spatial scale, work-related travel is exclusively plane-based and involves undertaking time-consuming, long haul flights which may cross multiple time zones (dependent on the locations being travelled between). Such journeys are typically inter-continental, but within the largest nation states such as Canada, China, the USA or Australia, such journeys may be intra-continental (for example travel between Brisbane and Perth, or between New York and Los Angeles). The number of managers and professionals who regularly and consistently engage in this type of travel is likely to be relatively small, with such travel patterns being confined to quite senior managers and professionals. However, less senior staff may be undertake such journeys less frequently. 
Faulconbridge al al (2009) examine business travel patters at this scale in examining the purposes and type of work-related travel and other forms of mobility that occur within global professional service firms. One of their key arguments is that the negative consequence of this form of travel, such as its cost, the time involved in undertaking such journeys and the personal costs people experience from undertaking such journeys (jet lag, tiredness etc) are typically well recognized by such organizations. Further, they argue that in attempting to reduce these negative consequences and the amount of long-haul travel that needs to be undertaken, staff in professional service firms regularly use various forms of virtual, electronic mobility to communicate with remote others and undertake work. Thus, arguably, email, phones and video conferencing represent forms of electronic mobility which are equally as important as the physical mobility undertaken by business travellers. However, while such forms of electronic mobility reduce the need for workers to undertake work-related journeys, they do not wholly the need for such journeys to be undertaken. One of the organizational activities which is arguably facilitated by some degree of face-to-face interaction, and which thus requires people to undertake business trips to achieve it, is managing and controlling the workforce within multinational corporations where staff are globally dispersed (Faulconbridge \& Muzio 2008, Jones 2010, 2013). It is corporate activity of this type which provides the illustrative example of this type of mobility.

Within global corporations, regular long-haul plane-based travel is most typically confined to relatively senior, corporate level managers. For such staff, the purpose of these journeys is to undertake strategic corporate-level work, such as initiating relationships with potential collaborators, developing or implementing/enforcing corporate level strategies, or liaising strategically with new or existing clients. 
Analytically, workers who regularly engage in this type of travel are referred to by Sklair (2001) as the 'transnational capitalist class', with the capitalist class being defined as those who own and control the major means of production, distribution and exchange. Sklair argues that this elite cohort can be divided into four fractions, with the dominant one being executives from transnational corporations. This represents what the dominant element of the transnational capitalist class. A second, less significant fraction of the transnational capitalist class is 'globalizing professionals', which represents the owners and partners of global professional service firms who have corporate level responsibilities.

While, as outlined, travel at this scale is exclusively undertaken by plane, due to the seniority of the people who regularly engage in this form of travel, people may often travel business or first class, rather than economy, or at the most senior levels, may even involve private rather than scheduled flights (Budd 2010). However, despite such workers travelling by these modes of transport, the quantity and type of travel being undertaken (in terms of the length of journeys, the fact that they impact on non-work time and involve travelling across multiple time zones) means that the work-related travel they engage in is likely to have a number of personal negative consequences.

\section{Conclusion}

The chapter has built from the foundational idea, embodied in Castells' vision of the contemporary network society (1996) that the mobility or 'flow' of people (among many other things) is intrinsic to economic activity in a globalized world which 
increasingly requires dispersed collaboration. In conceptualizing the diversity of workrelated mobility patterns engaged in by managerial and professional workers, it was argued that issues of spatial scale were neglected, resulting in a somewhat narrow focus on particular types of work-related journey. While long-distance, plane-based travel is an important type of work-related mobility, equally important types of work-related mobility are engaged in by managers and professionals at totally different spatial scales, such as localized car-based travel.

Taking full and adequate account of the diverse spatial scales that are involved in the work-related mobility of managerial and professional workers is important for a number of reasons. Firstly, focussing purely on long-distance travel is likely to result in the amount of work-related mobility engaged in by managerial and professional workers being inaccurately recorded and underestimated. Thus, to fully understand the extent of work-related mobility undertaken by such workers, surveys should collect data on all types of journey, whether localized or long-distance. Secondly, journeys on different spatial scales are likely to be undertaken by different types of manager and professional for different purposes. Thus while frequent long-haul travel is likely to be undertaken primarily by senior staff to undertake activities such as managing and controlling activities across different sites, localized forms of mobility may be more common among more junior managerial and professional staff. Thus, fully accounting for spatial scale helps provide insights into the diversity in type of people who regularly require to travel for work, as well as the purposes for which they undertake these journeys. Finally, fully accounting for differences in the spatial scale of work-related journeys will help provide insights into the specific ways that different type of journeys 
impact on the workers undertaking them, whether that is in terms of travel-related stress and wellbeing, or work-life balance.

The distinction made here between four broad spatial scales and type of journey is not intended to be a stand-alone typology that can be used to understand the diverse type of work-related mobility engaged in by managerial and professional workers. Equally important dimensions of variation highlighted by the other typologies examined here include the frequency of travel, and the range of different locations that people require to travel to. The typology of journey types and spatial scales outlined here thus represents an important and neglected dimension of variation that requires to be incorporated with other key variables in order to provide a rich and full understanding on the mobility patterns engaged in by managerial and professional staff.

\section{$\underline{\text { References }}$}

Aguilera, A (2008) Business Travel and Mobile Workers. Transportation Research Part A, 42: 1109-1116.

Beaverstock, J. Faulconbridge, J. (2010) 'Official' and 'Unofficial' Measurements of International Business Travel to and From the United Kingdom: Trends, Patterns and Limitations. In, Beaverstock, J, Derudder B, Faulconbridge J and Witlox F (eds) International Business Travel in the Global Economy. Farnham: Ashgate.

Beaverstock J, Derudder, B Faulconbridge J and Witlox, F. (2010) International Business Travel and the Global Economy: Setting the Context. In, Beaverstock, J, Derudder B, 
Faulconbridge J and Witlox F (eds) International Business Travel in the Global Economy. Farnham: Ashgate.

Budd, L, Hubbard, P (2010) The 'Bizjet Set': Business Aviation and the Social Geographies of Private Flight. In, Beaverstock, J, Derudder B, Faulconbridge J and Witlox F (eds) International Business Travel in the Global Economy. Farnham: Ashgate.

Castells, M (1996) The Rise of Network Society. Oxford: Blackwell.

Cohen R (2010) Rethinking 'mobile work': Boundaries of Space, Time and Social Relation in the Working Lives of Mobile Hairstylists'. Work, Employment and Society 24(1): 65-84.

Faulconbridge, J, Muzio, D (2008). Organizational Professionalism in Globalizing Law Firms. Work, Employment and Society, 22: 7-25.

Felstead A, Jewson N, and Walters S (2005a) The Shifting Locations of Work: New Statistical Evidence on the Spaces and Places of Employment'. Work, Employment and Society 19(2): 415-431.

Ferguson H (2009) Driven to Care: The Car, Automobility and Social Work. Mobilities 4(2): 275-293.

Gustafson P (2006) Work-related Travel, Gender, and Family Obligations. Work, Employment and Society 20(3): 513-530.

Gustafson, P. (2012). Managing Business Travel: Developments and Dilemmas in Corporate Travel Management. Tourism Management, 33: 276-284. 
Hardill, I, Green, A (2003). Remote Working - Altering the Spatial Contours of Work and Home in the New Economy. New Technology, Work and Employment, 18: 212-222. Hislop D. \& Axtell, C. (2011) Mobile Phones During Work and Non-Work Time: A Case Study of Mobile, Non-Managerial Workers. Information and Organization, 21, 4156.

Jeong Y-J, Zvonkovic A, Sano Y and Acock A (2013) The occurrence and Frequency of Overnight Travel in the USA. Work, Employment and Society, 27(1): 138-152. Jones, A (2010) Understanding Mobility in Professional Business Services, In, Beaverstock, J, Derudder B, Faulconbridge J and Witlox F (eds) International Business Travel in the Global Economy. Farnham: Ashgate.

Jones, A (2013) Conceptualising Business Mobilities: Towards an Analytical Framework. Research in Transportation Business \& Management, 9: 58-66.

Knox, H, O’Doherty, D, Vurdubakis, T, Westrup, C (2008) Enacting Airports: Space, Movement and Modes of Ordering. Organization, 15: 869-888.

Lassen, C Aeromobility and Work. Environment and Planning A, 38: 301-312.

Lilischkis, S. (2003). More yo-yos, pendulums and nomads: trends of mobile and multilocation work in the information society. Bonn, Germany: Empirica (STAR Issue Report No. 36.)

Millar, J Salt, J (2008) Portfolios of Mobility: The Movement of Expertise in Transnational Corporations in Two Sectors - Aerospace and Extractive Industries. Global Networks, 8: 25-50.

Salt, J (2010) Business Travel and Portfolios of Mobility. In, Beaverstock J, Derudder B, Faulconbridge J, Witlox F (eds) International Business Travel in the Global Economy. Farnham: Ashgate.

Sklair, L (2001). The Transnational Capitalist Class. Malden, Ma: Blackwell 
Travel Trends (2014) Travel Trends 2013. UK, Office of National Statistics.

Urry, J. (2000a), Sociology Beyond Societies: Mobilities for the Twenty-first Century, London: Routledge.

Vartianen M., Hakonen M., Koivisto S., Mannonen P., Mieminen M., Ruohomaki V. \& Vartola A. Distributed and Mobile Work: Places, People and Technology. Helsinki: Otatieto, 2007.

Wibberley G (2013) Getting the Bodies of the Workers to the Bodies of the Clients: the Role of the Rota in Domiciliary Care. In: Wolkowitz C, Cohen R, Sanders T and Hardy K (eds) Body/Sex/Work. Basingstoke: Palgrave Macmillan.

Wickham, J. Vecchi, A (2010) Hierarchies in the Air: Varieties of Business Air Travel. In, Beaverstock, J, Derudder B, Faulconbridge J and Witlox F (eds) International Business Travel in the Global Economy. Farnham: Ashgate. 
Table 1: Hierarchical Patterns in Work-Related Travel

\begin{tabular}{|c|c|}
\hline Work-Related Income & $\begin{array}{r}\text { Percentage of workers with } \\
\text { recent overnight work- } \\
\text { related travel }\end{array}$ \\
\hline Low & $3.4 \%$ \\
\hline Medium & $8.1 \%$ \\
\hline High & $25.1 \%$ \\
\hline
\end{tabular}

Adapted from Gustafson (2006, Table 1) 
Figure 1: Journey Type and Geographic Distance

Long-distance Land-based Journeys Long-Haul Plane-based Journeys Localized land-based Journeys Short-Haul Plane-based Journeys

Geographic Distance 